\title{
The socioecology of elephants: analysis of the processes creating multitiered social structures
}

G. Wittemyer ${ }^{*}{ }^{\dagger}$, I. Douglas-Hamilton ${ }^{\dagger, 1}$ and W.M. Getz ${ }^{*} \neq, 2$

*Department of Environmental Science, Policy and Management, University of California, Berkeley, U.S.A.

†Save the Elephants, Kenya

${ }^{\star}$ Mammal Research Institute, Department of Zoology and Entomology, University of Pretoria, South Africa

In this paper, we investigate the formation and function of the multilevelled, fissionfusion social structure in a free-ranging African elephant, Loxodonta africana, population. We quantitatively identified the existence of four social tiers by using cluster analysis on individual association data. We assessed the effects of season and study period on social structuring and levels of cohesion within and among social units. We found that second-tier units, potentially the equivalent of the 'family', were stable across seasonal periods but the number of units increased as the study progressed and the population grew. It appears that these units were sufficiently small not to be influenced by ecologically related factors, such as resource competition, that might otherwise lead to them splitting. On the other hand, third- and fourth-tier units were significantly affected by season in a way that suggests a trade-off between ecological costs (e.g. from resource competition) and different social and ecological benefits (e.g. from predator defence, territoriality, knowledge sharing and rearing of young). Age structure also appeared to influence this multitiered social organization. The size of second-tier social units was significantly affected by the age of matriarchs: units lead by matriarchs likely to be grandmothers (i.e. females 35 years and older) were significantly larger than those lead by younger matriarchs. We present a conceptual framework for understanding the 
emergence of multiple-tier social structure from interactions driven by socioecological processes. This study is the first to use rigorous quantitative methods to statistically show the existence of four hierarchical tiers of social organization in a nonhuman animal. Additionally, our results elucidate the role that ecological processes play in producing complex social structures.

\section{Article Outline}

Methods

Study area

Data collection

Difference from random structure

Structuring

Correlative coherence analysis (CoCA)

Statistics

Results

Differences from random structure

Seasonal and temporal data set analysis

Discussion

Seasonal effects on sociality

Temporal effects on sociality

Social unit stability and composition

Cohesive and divisive social forces

Acknowledgements

References

Ecological constraints, by impacting both mating systems and population structure, are formative factors in the evolution of social systems (Clutton-Brock and Harvey, 1977 and Emlen and Oring, 1977). In combination with their genetic underpinnings, the type and structure of individual-based interactions relates to the abundance and distribution of 
food or predation (Alexander, 1974, Wrangham, 1980, van Schaik, 1989 and Isbell, 1991). The socioecological hypothesis serves as a framework for studies of this particular relationship between ecological factors and social behaviour (Emlen and Oring, 1977, Vehrencamp, 1983, Terborgh and Janson, 1986, Emlen, 1995 and Kappeler and van Schaik, 2002).

The ecological factors affecting sociality vary across time and space. Ecological and social costs and benefits play a role in determining social unit size in fission-fusion societies (Devore and Washburn, 1963 and Kummer, 1968). Fission-fusion societies limit the effect of within-unit competition through unit splits during periods of high competition (Dunbar, 1992 and Kummer, 1995) and they enhance cooperative effects through unit cohesion when the ecological costs of aggregating are low or benefits of sociality are high (Takahata et al., 1994 and van Schaik, 1999). Aggregating behaviour is generally thought to be a response to predation pressures (Hamilton 1971). Widely distributed food resources may promote the evolution of fission-fusion social organizations as a response to fluctuations in the costs of feeding competition (Schaller, 1972, Altmann, 1974 and Jarman, 1974). However, individual-based studies focusing explicitly on the variability of social unit structure in relation to ecological factors are few. Here we use individual association behaviour to assess the impacts of season and time on social unit composition and cohesion, looking at the influence of ecological factors on the social organization of a free-ranging African elephant, Loxodonta africana, population.

In many animals, social relations are enigmatic or cryptic and thus difficult to record (Whitehead 1997). Using Hinde's (1976) framework for the study of social behaviour based on interactions between individuals, recent work has used association indexes to assess the social properties of populations (Cairns and Schwager, 1987 and Whitehead, 1995). The objectives of studies using these methods are to test the deviation from randomness of animal associative behaviour and to identify preferred and avoided associates (Myers, 1983, Kerth and Konig, 1999 and Whitehead and Dufault, 1999). Despite the importance and variability of social layering in human societies (Freeman, 
1992 and Cummins, 2000), little attention has been given to such structuring in animal societies, apart from some work on cetaceans (see Mann et al. 2000). Building on these associative-based methods, we used clustering techniques to identify social delineation in elephant society. Our methods empirically substantiate previous inferential descriptions of six hierarchical tiers of organization (Buss, 1961, Laws, 1970, Douglas-Hamilton, 1972 and Moss and Poole, 1983): mother-calf units (tier 1), families (tier 2), bond/kinship groups (tier 3), clans (tier 4), subpopulations (tier 5) and populations (tier 6). Identification of the form and function of nested social tiers can serve to further studies of sociality in numerous animal species that have more than one level of social organization, such as prairie dogs (Hoogland 1995), cetaceans (Conner et al., 1992 and Mann et al., 2000), geese (van der Jeugd et al. 2002) and multiple primate species (Strier 2000). In this paper, we focus on the relationship between socioecological forces and the emergence of a multitiered social structure that appears to conform to the above six-layer paradigm. Identification of the primary factors influencing the fission-fusion process at each social tier provides insight into the ecology of a species and can enhance studies on the evolution of complex social structures.

Being generalist herbivores with low digestive efficiency, elephants spend $60-80 \%$ of each 24-h day feeding (Owen-Smith 1988). The patchy distribution of resources in savannah ecosystems, in combination with their heavy feeding requirements, makes elephants susceptible to intraspecific competition. Such competition in other animals limits both the size of social units and their proximity to one another (Jarman, 1974 and Clutton-Brock and Harvey, 1977). Slight variation in forage quality and quantity may have marked impacts on elephant interactions. To explore this, we examined social unit structural variation across the wet and dry seasons over a 4-year study period.

Furthermore, we looked at temporal changes in social structure to assess social dynamics occurring due to the longer-term process of population growth. Potential benefits derived from the described social structure are also discussed. Building upon the socioecological framework, this study focuses on the factors influencing individual social behaviour and their relation to the fission-fusion social dynamic in a multitiered social organization. 


\section{Methods}

Study area

Samburu and Buffalo Springs National Reserves are small, protected areas in the greater Samburu/Laikipia ecosystem of northern Kenya. These reserves are used by the largest elephant population (numbering approximately 5200 individuals) that resides primarily outside protected areas in Kenya (Omondi et al. 2002). As a result of heavy tourist use of the parks, the elephants using these reserves are habituated to vehicles, enabling easy observation of their behaviour. Between November 1997 and May 1999, all elephants using the two reserves were individually identified and tentatively categorized into two subpopulations, termed resident and nonresident, based upon their degree of reserve use (Wittemyer 2001). The parks are unconfined and the primary landuse in this semiarid region is livestock grazing in communally owned group ranches that have few or no fences.

The majority of the observations in this study were collected within the boundaries of Samburu and Buffalo Springs National Reserves during June 1998-August 1999 and May 2000-December 2002. The total study area lies within $0.3-0.8^{\circ} \mathrm{N}, 37-38^{\circ} \mathrm{E}$. Samburu and Buffalo Springs National Reserves are $320 \mathrm{~km}^{2}$, constituting less than $2 \%$ of the greater Samburu/Laikipia ecosystem and generally $15-25 \%$ of the study elephants' home range (unpublished global positioning systems radiotracking data). The reserves are centred on the Ewaso Ngiro River, which is the only permanent water source in this semiarid region and, as such, a focal area for wildlife (for further description of the study area see Wittemyer 2001).

This region is drought prone and rainfall is sporadic, with the majority of rain falling during the two wet seasons in April and November. Because rainfall is unpredictable, seasons were defined using daily rainfall totals collected on the reserve boundary. Dry seasons were defined as beginning after 30 days without rain. Wet seasons were defined as beginning after 1 week with a minimum of $15 \mathrm{~mm}$ of rain (the approximate amount of precipitation required to observe a vegetative response). Single day showers between 2week periods of no rainfall were not considered to represent a seasonal change. 


\section{Data collection}

For purposes of clarity, we define the following terms used throughout this paper to describe the social context of elephants.

(1) Aggregation: a collection of elephants in the wild observed at a particular time to be associated with one another (see below for spatially explicit definition of association).

(2) Cluster: structural unit of a tree constructed using clustering methods (Romesburg 1984).

(3) Tier i units: social or suprasocial units (assemblages of individuals defined from analysis of clustering results following the methods described below) within a hierarchical organization where tier $i$ units are composed of tier $i-1$ units, $i=2-6$. Our study focuses on the social behaviour of breeding female elephants, defined as individuals with dependent calves, because the distribution and organization of females are generally thought to relate to the pattern of resources and risks in their environment, whereas males organize themselves around the distribution of receptive females in time and space (Trivers, 1972 and Emlen and Oring, 1977). All females older than 20 years in the study population had at least one dependent calf. Generally, a breeding female is associated with her juvenile offspring $100 \%$ of the time, although this bond weakens as juveniles mature (10-13 years), with males dispersing from their mothers' social units after puberty (Douglas-Hamilton, 1972 and Moss, 1988). Such tight bonds result in identical association behaviour between a mother and her calf (tier 1 social units); thus, for purposes of analysis, these mother-calf units were treated as a single entity represented by the mother. Our analysis of social behaviour focused on the resident subpopulation (tiers 5) comprising 112 breeding females and their calves, representing 382 elephants and $46 \%$ of the total population (tier 6 ) of breeding females identified within the study area (Wittemyer 2001).

The majority of observations used in this study were collected by observers recording all individuals encountered along one of four set routes travelled daily. Routes followed existing roads running the length of the reserves both to the north and south of the Ewaso Ngiro River. Routes 1 and 2 were within 500 m of either riverbank and routes 3 and 4 were located approximately $5 \mathrm{~km}$ from the river on either side. Observations of elephant 
aggregations during nontransect movements in the study area (opportunistic sampling) were also recorded and used in this study. All observations were recorded following the same protocol. Once elephants were spotted, observers approached to within $100 \mathrm{~m}$ or less of the aggregation and recorded the following data: (1) identity of individuals present; (2) accuracy of the observation (recorded in categories: (a) 100\% identification of all individuals; (b) identification of all breeding females and males excluding calves; and (c) incomplete identification); (3) location of aggregation; and (4) the date, time, observer name and route name. The observer stayed with the aggregation until all individuals were recognized, unless thick vegetation did not allow a complete accounting. The data presented in this study have been compiled from 2889 observations of aggregations for which the observer was confident of registering all associating breeding females (i.e. observation accuracy categories 1 and 2). Each individual's aggregation was recorded only once per day to avoid nonindependence of observations. In all instances of multiple observations per day, the first observation was retained to avoid potential observer (preordained) bias regarding the location or social context of individuals. The mean number of observations per breeding female was 132 (range 73-284).

Elephant aggregations, for calculation of association indexes, were defined as individuals estimated to be within a 500-m radius of an observationally estimated aggregation centre (elephants are generally clustered within a small area, thus social aggregations are easily recognized). When aggregations exceeded this 500-m radius criterion, we defined an aggregation as being separated from the nearest other aggregation by a distance greater than its diameter. To standardize observations between the individuals used in the study, aggregation data were converted into simple association indexes between all dyads in the study population (Ginsberg \& Young 1992) by using the equation: $\frac{Y_{\text {se }}}{*-L_{2}}$ where $X_{\mathrm{AB}}$ is the number of observations during which $\mathrm{A}$ and $\mathrm{B}$ were together, $N$ is the total number of observations, and $D$ is the number of observations during which neither A nor B were observed (thus including only observations when A or B were observed). Because association indexes are a ratio of the total observations of two individuals together and separate, results are robust against sample size differences between individuals. 


\section{Difference from random structure}

Previous studies of social structure based on individual association behaviour focused on assessing the differences between observed and random patterns of association (Manly 1995; Bedjer et al. 1997; Whitehead 1997). We applied these established methods to our elephant association data to verify that observed elephant associations deviated from random. SOCPROG 1.2 (Whitehead 1999) performed this analysis by generating random association data sets by switching 1 (associated) and 0 (not associated) values in rows of recorded association data (Bedjer et al. 1997). These random data sets were constrained such that the number of observations per individual and group sizes per observation matched the original data, and were then used for comparison with actual indexes of association to identify nonrandom properties of the study system (Bejder et al. 1997). Additionally, SOCPROG 1.2 offered a method for assessing the change in individual association behaviour through time by estimating the probability that two animals will associate at the same level across time lags (Whitehead 1995). We ran 20000 routines to assess the robustness of associations over time, as described in Bejder et al. (1997). To evaluate preferences in associations, observation data must be partitioned into sampling

periods. A sampling period of 10 days was selected for this analysis, because the primary observer was able to cover all sampling routes at least twice within this period, increasing the likelihood of encountering all elephants present. All possible sample periods were assessed in the analysis of lagged association rates (Whitehead 1995).

\section{Structuring}

Hierarchical social tiers were defined through a two-step analysis used to identify emergent properties of the association data. In the first step, a cluster analysis (the simplification of multidimensional information into a two-dimensional representation) of the raw data was conducted to objectively represent the structure of the study population (Strauss 2001). To determine the most appropriate clustering method for our data, we assessed the degree to which cluster results fit the observed data using the cophenetic correlation coefficient (CCC; Romesburg 1984). Only clustering results with CCC values greater than 0.8 (the accepted standard; Romesburg 1984) were used in the second step. In step 2, for each of the clustering trees we obtained, we created a cumulative graph of 
the number of bifurcations (branches) occurring per 0.05 bifurcation distance $(d)$ increment (the bifurcation distance is the $Y$ axis of a cluster tree, increasing up the tree as the degree of association between individuals decreases). This cumulative bifurcation graph was then used to identify putative knots, defined as points on the cluster tree where the rate of bifurcations below the knot was significantly different from rates above the knot (see below for further description). Thus, knot values indicate points of structural changes in the cluster method tree and were subsequently defined as social tier delineations.

We created hierarchical trees and cumulative bifurcation graphs for association data on all 112 breeding females in the study subpopulation (Romesburg, 1984 and Strauss, 2001) using four different clustering methods: the unweighted pair-group method (UPGMA), Ward's weighted method (Ward's), complete linkage method (CLINK), and single linkage method (SLINK) were compared (Table 1). Ward's method yielded the highest CCC value (Table 1) and, consequently, the results of that method were used in subsequent analyses to identify social tiers. We assessed the significance of all potential putative knots (points around which the slope of preceding and succeeding points changed) in the cumulative bifurcation graph by comparing the distribution of bifurcations per stepwise increment above versus below the knot values using the Wilcoxon two-sample test. The Wilcoxon two-sample $Z$ statistics of all contiguous, significant knots were compared and the putative knots that maximized these statistics were used to delineate social tiers (Fig. 1). The bifurcation value associated with the selected knot was then used to define the social units of the defined social tier where individuals bifurcating below the knot value were considered to be part of the same social unit (Fig. 2). To assess the integrity of the defined social units, the compositions of social units characterized using each of the four clustering techniques independently were compared (Table 2). 
Table 1.

The cophenetic correlation coefficients (Romesburg 1984) derived using four clustering methods

\begin{tabular}{|l|l|l|}
\hline Method & Total breeding females & Matriarchs of 2nd-tier units \\
\hline UPGMA & 0.874 & 0.529 \\
\hline CLINK & 0.890 & 0.575 \\
\hline SLINK & 0.841 & 0.479 \\
\hline Ward's & 0.965 & 0.820 \\
\hline
\end{tabular}

UPGMA: unweighted pair-group method; CLINK: complete linkage method; SLINK: single linkage method; Ward's: Ward's weighted method.

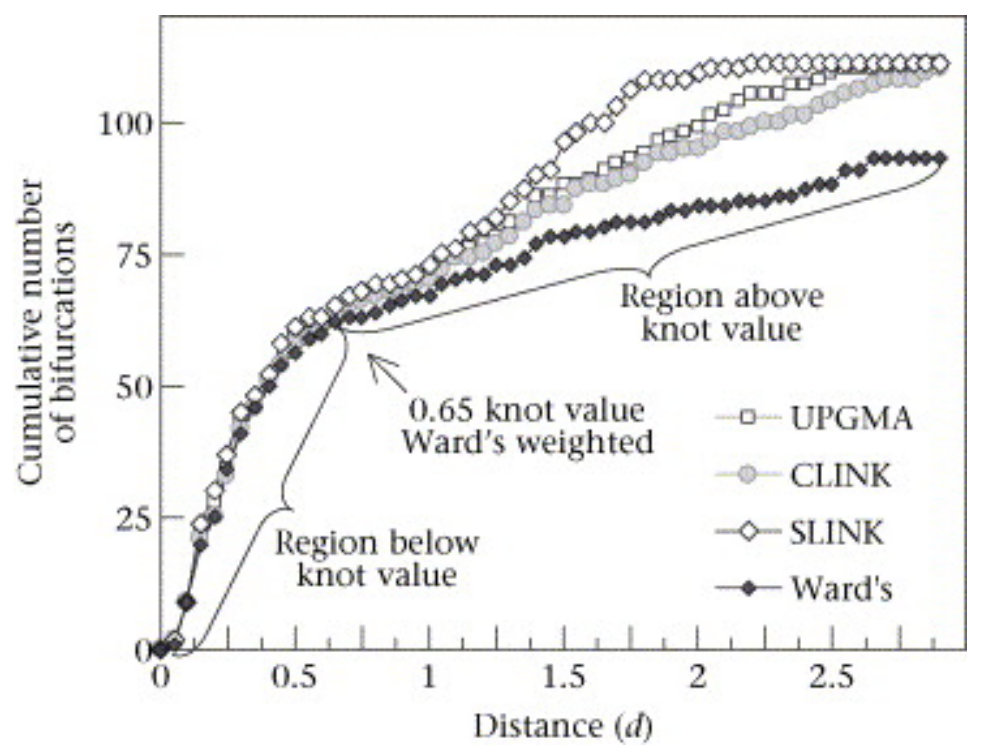

Figure 1. Cumulative numbers of bifurcations across cluster distances $(d)$ for the four different types of cluster analysis listed in Table 1 and Table 2. Identification of knot values signifying social tier delineations was conducted by maximizing $Z$ statistics from comparisons of stepwise changes above and below the knot value. The $0.65(d)$ knot value for the Ward's weighted clustering method is indicated, as well as the corresponding regions above and below the knot value $\left(Z=4.823, N_{\mathrm{A}}=27, N_{\mathrm{B}}=13\right.$, $P<0.0001)$. 


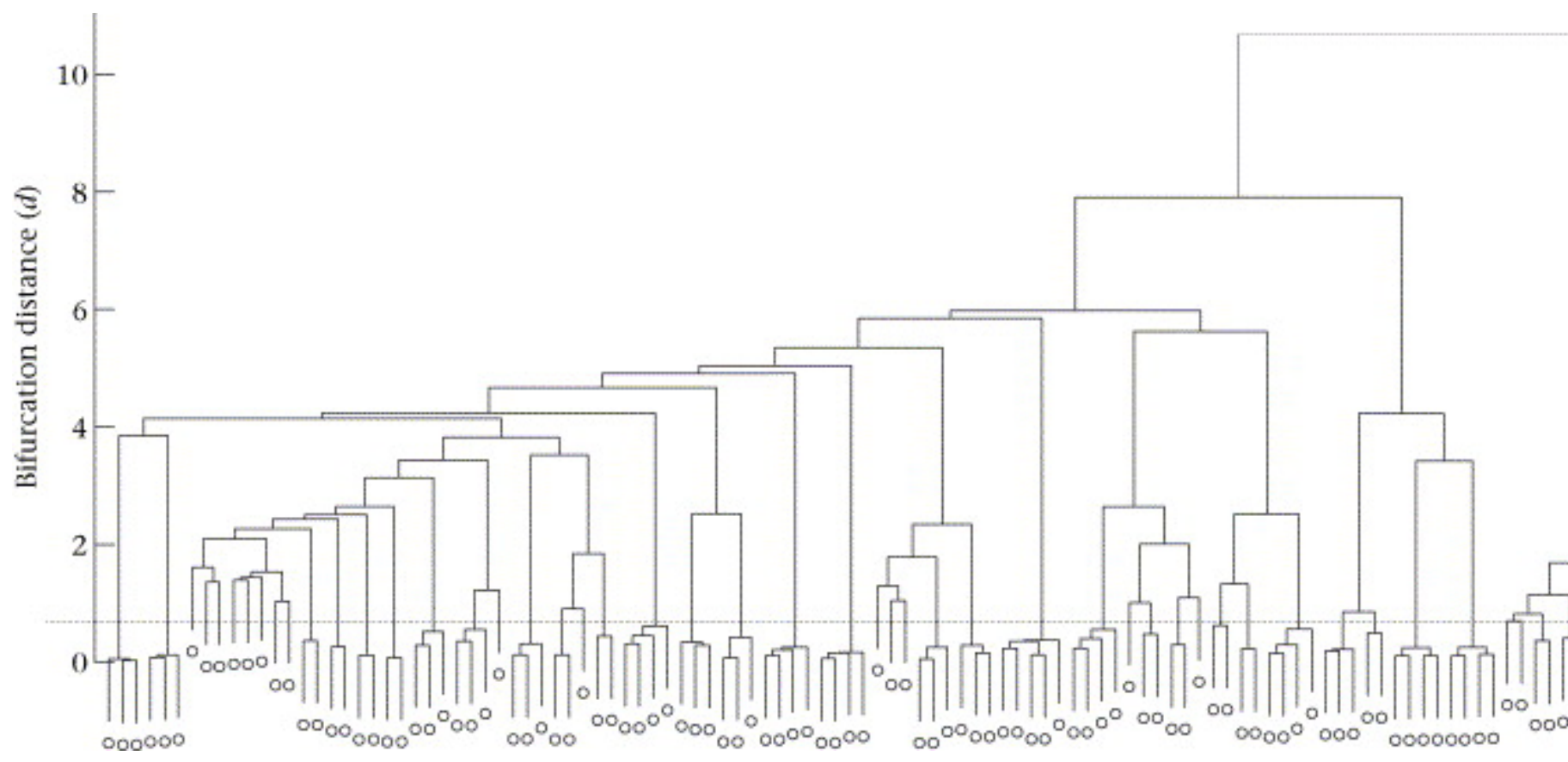

Figure 2. A cluster diagram constructed from the association indexes using the Ward's weighted method showing putative group relationships between the 112 breeding females used in the study. Each circle at the base of the tree represents one breeding female. The bifurcation distance $(d)$ is the measure of associative distance between individuals, where $d=0$ indicates that two individuals were observed together during $100 \%$ of observations (having the same association pattern) and increasing $d$ values represent decreasing degrees of association between individuals. The dotted line indicates the $d=0.65$ cutoff used to delineate second-tier social units from higher-order social relations (see Table 1 and Figure 1). Individuals bifurcating below this line are in the same second-tier unit, whereas those bifurcating above this line are in different second-tier units. 
Table 2 .

Results from four cluster methods used to assess the integrity of second-tier social unit definitions

\begin{tabular}{|l|l|l|l|l|l|l|}
\hline Method & Knot value & $\boldsymbol{N}_{\mathbf{A}}$ & $\boldsymbol{N}_{\mathbf{B}}$ & $\boldsymbol{Z}$ & $\boldsymbol{P}$ & Defined units \\
\hline Ward's & 0.65 & 27 & 13 & 4.823 & $<0.0001$ & 50 \\
\hline UPGMA & 0.55 & 29 & 11 & 4.867 & $<0.0001$ & 50 \\
\hline CLINK & 0.60 & 28 & 12 & 4.816 & $<0.0001$ & 50 \\
\hline SLINK & 0.50 & 30 & 10 & 4.295 & $<0.0001$ & 51 \\
\hline
\end{tabular}

Abbreviations as in Table 1.

Significant knot values $(P<0.05)$ separate sets of points that can be fitted with lines of different slope above and below the knot. The formation of units above and below the knot thereby occurs at different rates for a given rate of increase in the bifurcation distance variable $d$. Biologically, the knot indicates where the type of affiliation between individuals in merging clusters is changing from that of a tight, high association index (AI) value to a looser, lower AI value. Lower AI values are related to longer-term fissions of component groups within a cluster or more frequent rates of fission and fusion of these groups. In social systems where individuals associate at random, knots separating clusters into tiers that aggregate at different rates are not expected to be evident (Fig. 3). In our case, the graph is distinctly concave down, suggesting that the primary social tier (comprising the greatest number of bifurcations) occurs at a high AI level, followed by more loosely associated upper tiers with fewer bifurcations. Biologically, this implies the core social tier is composed of stable, tightly associated units, which are potentially coalitions or kinship-based groups such as families. This contrasts with social systems producing concave-up graphs, where a high density of linkages occur in an upper tier predicated by a few individuals associating in the lower tier level. Biologically, this would indicate that the primary social structure is a relatively unstable, looser aggregation of individuals, potentially in the form of a loose herd. 


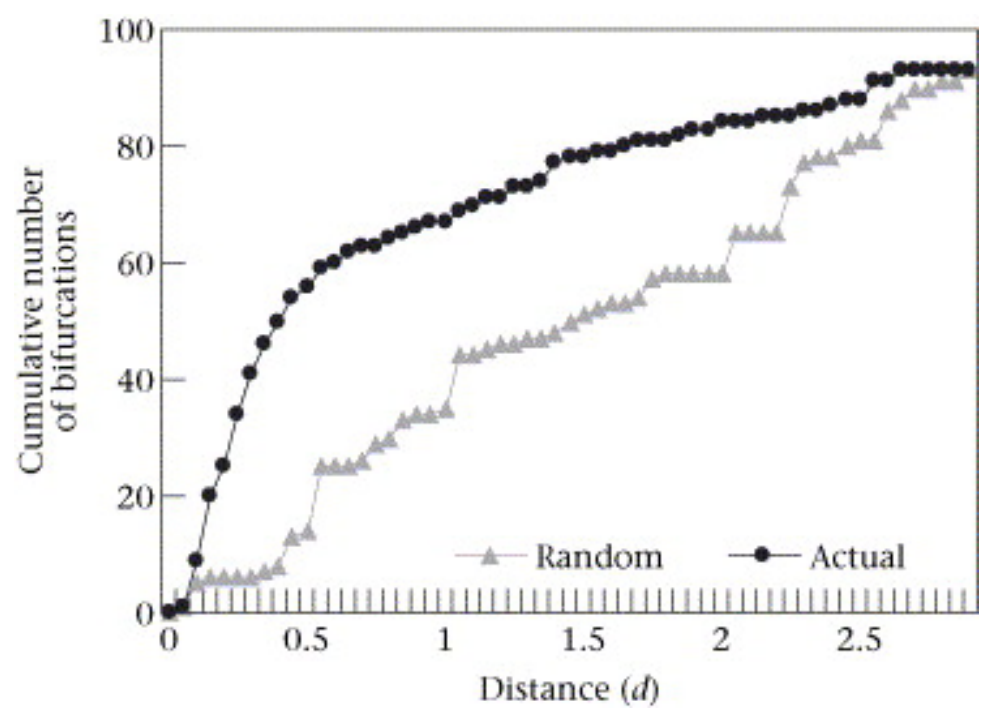

Figure 3. The difference between the cumulative number of bifurcations across cluster distances $(d)$ for actual association data (from the Ward's clustering method) and the data after randomization. The randomized data set did not have any significant knot values and was relatively linear, indicating that no social tiers existed. The actual data showed a significant knot value $(P<0.05)$ at $0.65(d)$ and was concave down, indicating the existence of a social tier.

After definition of second-tier units, the data were reduced to include only associations among the matriarchs of each second-tier unit (see below for definition of matriarch) to identify higher-order social tiers. The strengths of second-tier associations inundate the weaker higher-order relationships; thus, all relationships below the identified second-tier knot value were excluded from this subsequent analysis. Ward's clustering method, subsequently run on the reduced association matrix, was the only method that yielded a CCC value greater than the 0.80 standard ([tb11] and Romesburg, 1984). Consequently, it was the only method we used in the analysis of defined social units at levels above the second tier. Furthermore, multiple significant knot values emerged in two of the data partitions (described below) from this analysis (the wet season and 1998-2000 data, whereas the other sets did not contain more than one significant knot; see Results and Discussion). Identification of multiple knots followed the same procedure as the analysis conducted for the second tier with the additional method of repeated comparisons of 
potential knots to maximize the sum of $Z$ statistics for both knots simultaneously. The two significant knots were used to delineate three social tiers: third-tier units were defined as the consortium of second-tier units whose bifurcation points lay below the first knot of the matriarch tree, fourth-tier bifurcation points lay between the first and second knot, and the subpopulation (potentially the fifth-tier social delineation) used in this study lay above the second knot (Fig. 4).

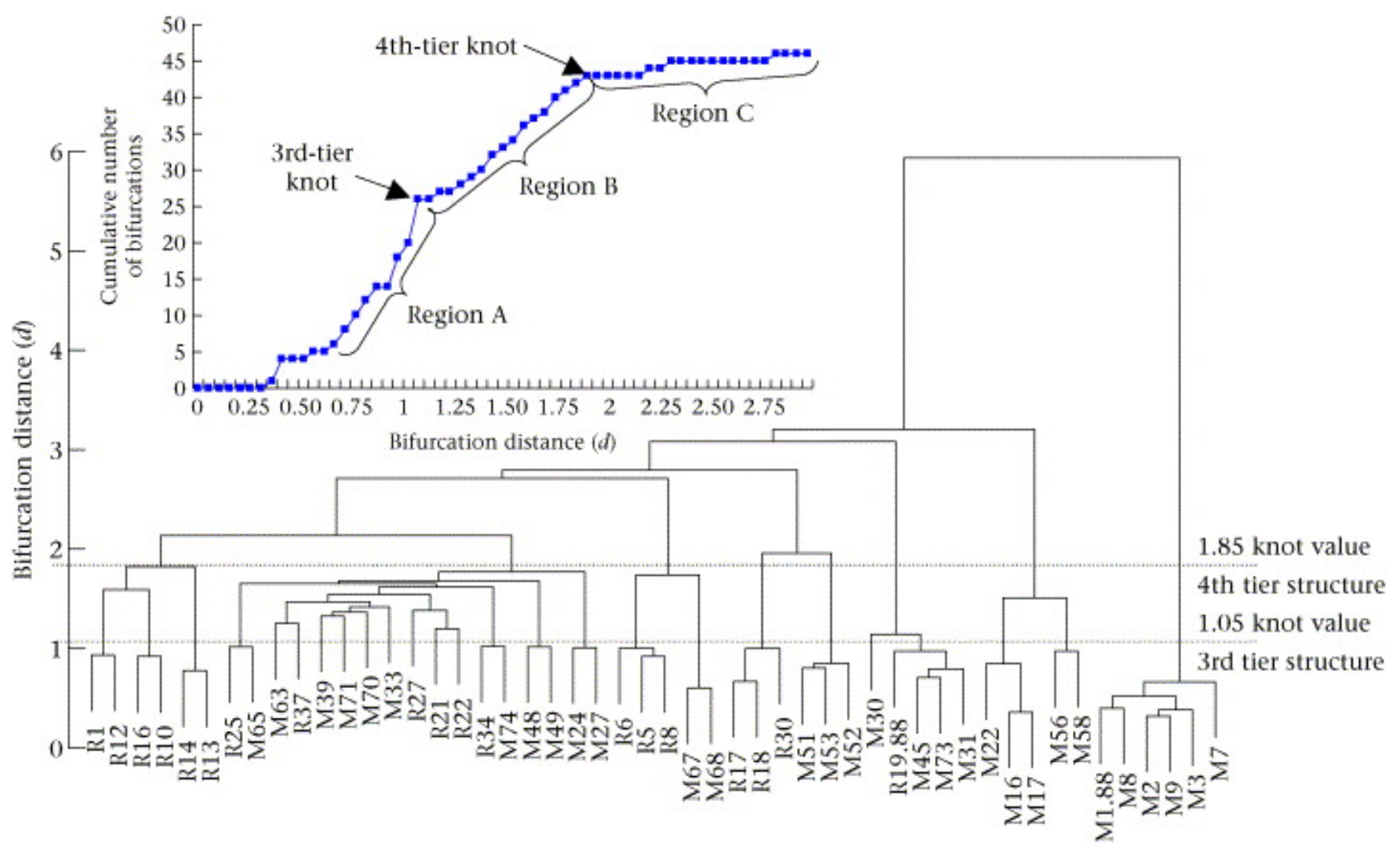

Figure 4. The Ward's cluster diagram and the cumulative bifurcation graph plotted for the 50 second-tier unit matriarchs (listed as letter and number combinations at the base of the cluster tree) using wet season data only. The third (Region A, $0.65<d \leq 1.05$ ) and fourth (Region $\mathrm{B}, 1.05<d \leq 1.85$ ) social tiers are identified by the slope changes in the cumulative graph of bifurcations (Inset). Region $\mathrm{C}(d>1.85)$ is where the fourth-tier units aggregated to form the fifth-tier subpopulation associated with the study site. Social delineations occur at statistically optimized knot values (see Methods) after all points below $d=0.65$ have been removed (these represented second-tier units based on a cluster 
analysis of all the data). The significances of the knots were: A versus B: $Z=2.527$, $P=0.012$; B versus $C: Z=3.926, P<0.001$. A statistically significant third-tier delineation was not distinguishable from the fourth-tier delineation in our analysis of dry season data alone $(Z=1.324, P=0.185$; Table 4$)$.

For evaluation of ecological and temporal effects on social structure, matrices of association indexes from observations during the wet and dry seasons and temporal periods 1998-2000 and 2001-2002 were created. The numbers of aggregations recorded for each partition were (seasonally) 1795 during dry periods and 1094 during wet periods, and (temporally) 1404 during 1998-2000 and 1485 during 2001-2002. Differences in the number of observations in the dry versus wet seasons relate to differences in the length of each season (dry periods are typically longer) as well as the tendency of elephants to aggregate in fewer, larger groups during the wet season. Analyses of both seasonal and temporal association matrices were conducted using the methods described above. Structures from each partition were compared with results from the total data set to ascertain the degree of social stability. Social stability was assessed in two manners: (1) as individual stability, defined as the number of individuals assigned to the same units as found with the total data set and (2) as unit stability, defined as the number of units with identical compositions to those defined from the total data set, where a unit is unstable even if a single individual changes membership (Table 3). These analyses provide information on the variation in social structuring seen across seasons, or ecologically distinct periods, and time, or periods differentiated through demographic changes. Furthermore, the social networks of individuals (the number of total study animals with which an individual was observed to associate) were compared across seasonal and temporal partitions using paired statistics. 
Table 3 .

Effects of season (ecological variability) and time (population growth) on social structure

\begin{tabular}{|c|c|c|c|c|c|c|c|c|}
\hline Delineation & $\begin{array}{l}\text { Knot } \\
\text { value }\end{array}$ & $N_{\mathrm{A}}$ & $N_{\text {B }}$ & $Z$ & $\boldsymbol{P}$ & $\begin{array}{l}\text { Defined } \\
\text { units }\end{array}$ & $\begin{array}{l}\text { Different } \\
\text { individuals }\end{array}$ & $\begin{array}{l}\text { Identical } \\
\text { units }\end{array}$ \\
\hline \multicolumn{9}{|l|}{ 2nd-tier } \\
\hline Total & 0.65 & 27 & 13 & 4.823 & $<0.0001$ & 50 & & \\
\hline Wet & 0.6 & 28 & 12 & 4.67 & $<0.0001$ & 49 & $3 *$ & $45 \dagger$ \\
\hline Dry & 0.75 & 25 & 15 & 4.482 & $<0.0001$ & 49 & $2 *$ & $48 \dagger$ \\
\hline $1998-2000$ & 0.6 & 28 & 12 & 4.533 & $<0.0001$ & 49 & $5^{*}$ & $44 \dagger$ \\
\hline $2001-2002$ & 0.45 & 31 & 9 & 4.586 & $<0.0001$ & 56 & $6^{*}$ & $44 \dagger$ \\
\hline \multicolumn{9}{|l|}{ 3rd-tier } \\
\hline Total & 1.1 & 14 & 9 & 1.185 & 0.2359 & - & & \\
\hline Wet & 1.05 & 16 & 9 & 2.527 & 0.0115 & 25 & - & - \\
\hline Dry & 1.15 & 10 & 8 & 1.324 & 0.1854 & - & - & - \\
\hline 1998-2000 & 1.3 & 14 & 14 & 2.429 & 0.0151 & 20 & - & - \\
\hline 2001-2002 & 1.05 & 14 & 12 & 1.582 & 0.1070 & - & - & - \\
\hline \multicolumn{9}{|l|}{ 4th-tier } \\
\hline Total & 1.8 & 17 & 14 & 4.247 & $<0.0001$ & 8 & & \\
\hline Wet & 1.85 & 19 & 16 & 3.926 & $<0.0001$ & 8 & $0 \ddagger$ & $8 \S$ \\
\hline Dry & 1.65 & 24 & 10 & 4.229 & $<0.0001$ & 10 & $10 \ddagger$ & $5 \S$ \\
\hline $1998-2000$ & 2 & 16 & 14 & 2.834 & 0.0046 & 8 & $2 \ddagger$ & $6 \S$ \\
\hline $2001-2002$ & 1.65 & 18 & 14 & 4.062 & $<0.0001$ & 9 & $6+$ & $6 \S$ \\
\hline
\end{tabular}

Statistical identification of knot values and subsequent unit definitions were conducted by comparing stepwise changes in the number of bifurcations above the knot value $\left(N_{\mathrm{A}}\right)$ and below the knot value $\left(N_{\mathrm{B}}\right)$ (see Methods and Fig. 1).

* Of 112 individuals.

${ }^{\dagger}$ Of 50 units. 
\$ Of 50 individuals.

$\S$ Of 8 units.

The matriarch of a social unit was defined, on the basis of behavioural observations, as the individual that was dominant to all other unit members (where dominant individuals physically displaced subordinate individuals from resources). Age estimates of matriarchs were conducted using physical features such as shoulder height, body length and facial features (Moss 1996). The ages for 16 breeding females have been assessed through molar evaluation (a method with an approximate error of \pm 2 years; Laws 1966) either after death or during radiocollaring operations (Rasmussen et al., in press). Differences between our estimates and molar-evaluated ages were minor, with a mean $\pm \mathrm{SE}$ of $2.5 \pm 1.5$ years, and estimates based on other physical features were generally greater than molar-evaluated ages. Individuals of known age were then used for comparison with estimated individuals.

Correlative coherence analysis (CoCA)

Previous studies have used the mean and standard deviation of association index values to look at differences in individual associations (Myers, 1983 and Gowans et al., 2001). In a population of size $n$, the average is taken over $\frac{\frac{n y_{f}-1}{2}}{2}$ pairwise indexes. These indexes, however, are partially correlated with each other and thus not independent, particularly in social units of closely associated individuals such as those found in second- and third-tier units. Correlative coherence analysis (CoCA; Getz 2003) accounts for the fact that a group of $n$ individuals only has $n-1$ degrees of freedom when finding a single value to represent the 'average' degree of association among $n$ individuals, and thus is not susceptible to potential problems with nonindependence. Correlative coherence analysis produces a single number that generalizes the concept of association from two to $n$ individuals and was developed to generalize the concept of the correlation between two sets of measurements to the correlation among $n \geq 2$ sets of measurements (Getz 2003). Association indexes between pairs of individuals, because they range from 0 to 1 , are equivalent to non-negative correlations between these pairs of individuals. The method for computing the $\mathrm{CoC}$ value of an $n$-dimensional associate matrix $\mathbf{A}$ is as follows (Getz 
2003). Calculate the $n$ eigenvalues $\lambda_{\mathrm{i}}(i=1, \ldots, n)$ of $\mathbf{A}$. The $\mathrm{CoC}$ value of $\mathbf{A}$ is then the solution $r$ to the equation

$$
\begin{aligned}
& (1+\{n-1) p) \ln (1+(n-1) p+(n-1)(1-p) \ln (1-p) \\
& =\mu \ln m+\sum_{i=1}^{n} \lambda_{i} \ln \left(\frac{\hat{\alpha}_{i}}{F}\right) \text {. }
\end{aligned}
$$

We note that if all pairwise associations in a system had the same value, $r$, then their $\mathrm{CoC}$ value would also be $r$. In this sense, $r$ is an average measure. We also note that $\mathrm{CoC}$ and average AI values are similar in populations where all units have reasonably high levels of association or all units are similarly associated. Whenever the matrix A contains many zeros, then the $\mathrm{CoC}$ value greatly exceeds the average $\mathrm{AI}$ value. This is the reason for the striking differences in $\mathrm{AI}$ values and $\mathrm{CoC}$ values in the fouth-tier and population social levels in Table 4. Intuitively, the reason for this difference follows from the fact that for the three-unit system for which $a_{12}=a_{13}=a_{23}=1 / 3$ (i.e. all units associate $1 / 3$ of the time with each other), the CoC value $=1 / 3$, whereas for the system $a_{12}=1, a_{13}=a_{23}=0$, the $\mathrm{CoC}$ value $=0.702$. In both cases, the average value for $a_{i j}(i \neq j)$ is $1 / 3$, but in the latter case the measure of coherence should be much higher because we have two of the three units associating with one another all the time. From this example we obtain an intuitive feel for the reason why $\mathrm{CoC}$ values are more appropriate to assess group cohesion than are average AI values, particularly in populations where the level of association among units varies greatly between 0 and 1 .

\section{Table 4.}

Comparison of the average association index (AI) value and average social unit correlative coherence $(\mathrm{CoC})$ value across social tiers

\begin{tabular}{|l|l|l|l|l|}
\hline Delineation & AI & SE & CoC & SE \\
\hline 2nd-tier & 0.829 & 0.017 & 0.835 & 0.018 \\
\hline 3rd-tier & 0.627 & 0.037 & 0.706 & 0.030 \\
\hline 4th-tier & 0.376 & 0.058 & 0.515 & 0.036 \\
\hline 5th-tier & 0.053 & 0.001 & 0.281 & 0.001 \\
\hline
\end{tabular}




\section{Statistics}

Statistical analyses and all clustering methods were conducted using the software package S-Plus 6.0 (Insightful Corp., New York, New York, U.S.A.). Nonparametric statistical methods were used in this study except for comparison of seasonal social networks. The Wilcoxon paired-sample test was used for comparisons of the seasonal differences in social units' $\mathrm{CoC}$ values and two-tailed, paired $t$ tests were used to compare the distributions of social networks across seasons and temporal periods. Jackknife techniques were used to obtain estimates of variances for $\mathrm{CoC}$ values of nonreplicated events (i.e. the wet and dry matrices for the total population and matrices of a social unit before and after its matriarch's death; Shao \& Tu 1996). Median and interquartile range (IQR) values are presented for data sets compared with nonparametric techniques, and mean and standard error (SE) values are presented for normally distributed data.

\section{Results}

Differences from random structure

Using the methodology of Whitehead (1999), we found that the association behaviour of the Samburu elephant population differed significantly from random. Observed association indexes were significantly lower than random association indexes (observed $=0.085$, random $=0.093 ; P<0.0004)$, indicating that elephants maintained preferred associations within the 10-day sampling periods, which constrained the number of dyads associating (Whitehead, 1999 and Gowans et al., 2001). In addition, the standard deviation of observed association indexes was significantly greater than that of random (observed $=0.145$, random $=0.086 ; P>0.9999$; this large $P$ value for the two-tailed test specifies a significantly larger observed value than the random value), indicating that elephants maintained preferred associations across 10-day sampling periods. Lagged association rates are used to assess the duration of associations in a population, where the rate decreases across the period of the study if associations are short lived or remains constant if relationships are stable (Whitehead 1999). We found that lagged association rates decreased slightly during the first 7-10-day sampling periods and were relatively stable for all lagged durations exceeding 10 days (Whitehead 1995) 
Seasonal and temporal data set analysis

Compositions of defined second-tier social units were stable across the four clustering methods compared. Structurally, 50 units were defined from three of the four methods, with 51 identified from the fourth (Table 2). In comparison to Ward's method, which gave the greatest CCC value (Figure 2 and Table 1), only four of the 112 individuals were grouped differently in second-tier units defined from the three other methods combined. We used a reduced data set composed of only the 50 second-tier unit matriarchs for identification of higher social levels. Four distinct, hierarchical social tiers emerged from this analysis of interactions among elephants in the studied subpopulation. Delineations of breeding females into second-tier units, second-tier into third-tier units, and third-tier into fourth-tier units were defined statistically (Figure 4 and Table 4). Association data were partitioned by season (wet and dry) and year of study (1998-2000 and 2001-2002), and then analysed independently to allow comparison of results derived from temporal or seasonal effects. The explicit, individual compositions of second-tier units (i.e. family units; Buss, 1961, Laws, 1970 and Douglas-Hamilton, 1972) were largely stable across data set partitions. The greatest change occurred in the 2001-2002 partition where six of 112 individuals changed by splitting off to form new family units (Table 3). Both seasonal partitions showed greater consistency, with three (wet) and two (dry) individuals changing social units and with consistent numbers of social units (Table $3)$.

Our ability to separate third-tier from fourth-tier units, defined from relationships among second-tier matriarchs, was greatly affected by the seasonal partitioning. The delineation between these two tiers emerged only during the wet season, as neither dry season nor total data sets showed significant knot values (Table 3). Additionally, this delineation was evident only during the earlier stages of the study, in the 1998-2000 data set, although at a cohesively weaker level with $d=1.3$ (Table 3 ).

Social units of the fourth tier were the least cohesive and the most variable at both the individual and unit level during the dry season, where 10 matriarchs (20\%) were grouped in different fourth-tier units and only five (62.5\%) of the identified fourth-tier units were 
identical in composition to those from the total data set (Table 4). In addition, the number of fourth-tier units increased by two in the dry season in comparison with the wet season, and increased by one in the later half of the study as compared to the first half (Table 4). The 1998-2000 temporal data set was relatively stable with only two individual changes and $75 \%$ of units identical in composition to the total data set, whereas the 2001-2002 data set was less stable, with six individuals changing social units and $75 \%$ of units identical (Table 3).

Comparisons of cohesion between social tiers and between data partitions within social tiers were conducted using CoCA. This method quantified the average cohesion of a matrix while taking into account the correlation between matrix elements (Getz 2003). Correlative coherence and average AI values generally depicted the same trends in behaviour (Table 4) but $\mathrm{CoC}$ values were greater than the average AI values especially when many dyad AI values were zero, as in the fourth and fifth social tiers (see Methods for explanation of this difference). Previous studies have used the average AI value to compare social cohesion (Myers, 1983 and Gowans et al., 2001). As already noted, however, AI values are not statistically independent. Cohesion, as measured by CoCA, decreased from the second to the fifth tier, with the highest levels occurring among core second-tier units. Corresponding to the cluster method results, levels of cohesion differed significantly across each tier (Kruskal-Wallis test: $\chi_{3}^{2}=24.627, P<0.0001$; Table 4). Across all social tiers, seasonal effects on $\mathrm{CoC}$ values were apparent (Table 5). The $\mathrm{CoC}$ values of second-tier 'families' generally increased during the wet season as compared to the dry season, but the difference was not significant (Wilcoxon two-sample test: $Z=1.715, N=32, P=0.086)$. We used wet season definitions of third-tier 'bond/kinship' units to compare unit cohesion, and found that wet season $\mathrm{CoC}$ values were significantly greater than those of the dry season $(Z=234, N=23, P=0.002)$. Significantly greater cohesion was also found in fourth-tier 'clans' during the wet season than the dry season ( $Z=35, N=8, P=0.0156)$. However, nine of 50 second-tier, four of 25 third-tier, and one of eight fourth-tier units showed greater cohesion during the dry season than the wet. The fifth-tier subpopulation showed the same general seasonal effect found in tiers 2-4, with the wet season $\mathrm{CoC}$ value exceeding that of the dry season. Like cohesion, social 
networks increased in size significantly during the wet season when individuals associated with an average of 98 individuals (87.6\% of all study individuals), whereas dry season networks averaged 80 individuals (71.0\% of all study individuals; paired $t$ test: $\left.t_{111}=12.152, P<0.0001\right)$. However, social networks were not significantly different across temporal periods of the study $\left(t_{111}=1.285, P=0.201\right)$.

Table 5.

Correlative coherence $(\mathrm{CoC})$ values for social tiers 2-5 during the wet and dry seasons

\begin{tabular}{|c|c|c|c|c|c|c|c|c|}
\hline Delineation & $\begin{array}{l}\text { Wet } \\
\text { median } \\
\text { (CoC) }\end{array}$ & $n$ & IQR & $\begin{array}{l}\text { Dry } \\
\text { me- } \\
\text { dian } \\
\text { (CoC) }\end{array}$ & $n$ & IQR & $\begin{array}{l}\text { Wilcoxon } Z \\
\text { (exact) }\end{array}$ & $\boldsymbol{P}$ \\
\hline 2nd-tier & 0.875 & 32 & $0.780-0.924$ & 0.810 & 32 & $0.730-0.882$ & 1.715 & 0.086 \\
\hline 3rd-tier & 0.749 & 23 & $0.667-0.824$ & 0.645 & 23 & $0.602-0.791$ & $(234)$ & 0.002 \\
\hline \multirow[t]{2}{*}{ 4th-tier } & 0.536 & 8 & $0.478-0.605$ & 0.511 & 8 & $0.462-0.544$ & $(35)$ & 0.016 \\
\hline & $\begin{array}{l}\text { Wet } \\
\text { mean }\end{array}$ & & Jackknife SE & $\begin{array}{l}\text { Dry } \\
\text { mean }\end{array}$ & & $\begin{array}{l}\text { Jackknife } \\
\text { SE }\end{array}$ & & \\
\hline 5th-tier* & 0.305 & 1 & \pm 0.0164 & 0.272 & 1 & \pm 0.0159 & & \\
\hline
\end{tabular}

The numbers of units compared $(n)$ are less than the actual number of units in second and third tiers because comparisons across seasons were not possible in units composed of single breeding females.

* The fifth tier CoC values were jackknifed to obtain standard error estimates.

Demographic changes in the size of a second-tier unit through time are likely to influence its stability, and one might expect the sizes of second-tier and potentially third-tier units to be distributed around some ecologically and sociologically determined optimal size. Interestingly, we found no evidence for this: the distribution of the number of second-tier 
units comprising the 26 third-tier units was not different from random, as tested against a Poisson distribution of the same mean $\left(\chi_{2}^{2}=0.19277, P=0.9081\right)$. The distribution of individuals (breeding females and their calves) in the 50 second-tier units did deviate from random $\left(\right.$ mean $\left.=7.64, \chi_{11}^{2}=50.87, P<0.0001\right)$, but the distribution was bimodal (Fig. 5). We choose to organize these data into the sum of two distributions based on matriarch age (the generation time for elephants is 17.4 years (Moss 2001), so elephants twice the age of the generation time (34.8 years) are more likely than not to be grandmothers). Again, the distributions of each category based on matriarch age did not differ significantly from random (35 years and older: mean $=9.85, \chi_{12}^{2}=8.363$, $P=0.7562$; less than 35 years: mean $\left.=5.02, \chi_{5}^{2}=10.142, P>0.0713\right)$, indicating that an optimal group size did not exist when accounting for units with different age structure. Matriarchs younger than 35 years, however, led significantly smaller families than matriarchs 35 years and older $\left(\operatorname{median}_{\text {younger }}=4\right.$, median $_{\text {older }}=10$ : Wilcoxon two-sample test: $Z=4.666, N_{\text {younger }}=23, N_{\text {older }}=27, P<0.0001$ ); thus, matriarch age did have an effect on the size of social units.

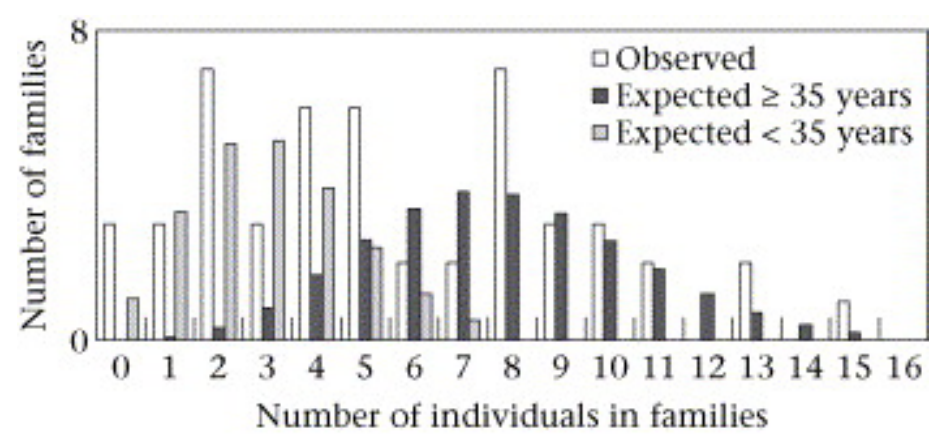

Figure 5. Second-tier unit size distribution and Poisson (expected) distributions of the same means.

\section{Discussion}

Elephants show stable, nonrandom social behaviour. Performing cluster analysis of association data, we were able to delineate four hierarchical social tiers from the continuum of social interactions. These four tiers showed significantly different degrees 
of cohesion (Table 4) and responded differently to temporal and seasonal effects. Individuals generally displayed strong unit fidelity across time and season, but fusions of lower-tier units into higher-tier units and fissions of higher-tier units into lower-tier units occurred regularly. Variability in unit composition across data partitions was generally the result of switches by a few individuals across social units (Table 3). Thus, the majority of individual social relations and the four-tier social organization were relatively consistent during the study period.

Previous studies of elephant social structure describe three social tiers, tiers 1-3, and three nonsocial tiers, tiers 4-6 (Douglas-Hamilton, 1972 and Moss and Poole, 1983). Our study is the first to quantitatively show this multitiered social structure. Our second-tier units correspond with the definition of family unit (Buss, 1961, Laws, 1970 and DouglasHamilton, 1972), which is a group of closely associated breeding females, most probably relatives, and their calves. Our third-tier units appear to equate with Douglas-Hamilton's (1972) description of kinship groups, later termed bond groups (Moss \& Poole 1983), which comprised on average 2.5 family units and 28 (range 14-48) individuals in Lake Manyara National Park. Similarly, third-tier units comprised on average 2.0 second-tier units and 16 (range 6-40) individuals in our study area. The difference in average size may be related to ecological differences between the two study areas, because Samburu is much drier than Lake Manyara. Previous research described a fourth-tier organization, termed clan, as a spatial population structure, roughly grouping elephants according to overlap in their dry season home ranges (Douglas-Hamilton, 1972 and Moss and Poole, 1983). The emergent fourth-tier delineation in our study does not rely on any spatial information and represents a potentially novel tier not previously recognized to be influenced by social fusions of second- and third-tier units. Furthermore, the dry season home ranges of all fourth-tier units overlapped and some units' ranges were not distinguishable spatially, indicating that the previous definition of clans (DouglasHamilton, 1972 and Moss and Poole, 1983) does not apply to the fourth-tier units defined in this study. 
This study examined social structure as a function of behavioural association patterns, although it is likely that spatial properties of the study population influenced observed social behaviour. Of particular interest is the influence of spatial interactions on the emergence of fourth-tier units. Our observations suggest that fourth-tier units are a function of social rather than spatial processes, as the data were collected within or near a small $\left(320 \mathrm{~km}^{2}\right)$, unfenced nature reserve. Elephant movements and resulting social interactions, therefore, appear not to have been constricted by distance, landscape features, or any geographical barriers. Furthermore, although some spatial structure was associated with the resource-rich river running through our semiarid study area, we did not identify any riparian structures that would explain the emergence of as many as eight fourth-tier units.

Observations of mutualistic interactions (Mann et al. 2000) among third- and fourth-tier unit members support our assertion that these tiers were social in origin. Radiotracking data on two third-tier associates from different second-tier units showed coordinated movements over periods greater than a month within and outside the protected study area (unpublished data). Similarly, observational data on fourth-tier associates indicate periods of cohesive movement spanning multiple weeks, both within and outside protected areas. Similar cohesive behaviour for shorter periods (7-14 days) has been recorded for the entire fifth-tier subpopulation. Coordinated behaviour such as this has been used to distinguish social from nonsocial structures in studies of cetaceans (Whitehead 2003). Furthermore, large aggregations ( $>100$ elephants) were assembled in relation to social tiers, where fourth-tier members were usually spatially clustered within the larger aggregation and third- and second-tier units were spatially nested within their fourth-tier units. Observations of alloparental care were common within second- and third-tier units and occurred infrequently among fourth-tier relations. Specifically, lactating females were observed suckling another second-tier associate's calf in four different units and a third-tier associate's calf in two different units. Such interactions are rare and were not observed across different fourth-tier units. Nonlactating females, however, were observed to suckle calves within second-, third- and fourth-tier units although such behaviour was generally limited to calves less than 6 months old and was infrequent across higher tier 
associates. Although rates of this interaction were not rigorously recorded across the population, the significance of this behaviour has been studied (Lee 1987). Individuals defending their second- and third-tier counterparts were also common, and coalitions of fourth-tier units in response to dominance interactions with outside elephants were observed infrequently. These observations suggest a social rather than nonsocial mechanism in the formation and maintenance of the fourth-tier social organization.

Seasonal effects on sociality

During the dry season, when resource quality and quantity decreases, ecological constraints increase inter- and intragroup competition (Altmann, 1974 and Jarman, 1974). The socioecological framework predicts that this increase in competition should shape the social structure of organisms (Wrangham, 1980 and Isbell, 1991). Our results indicate that social cohesion of elephant units decreases across all social tiers during the dry season. However, the effects of the dry season are disproportionate across tiers. Secondtier units were the most stable across seasonal and temporal partitions (Table 3 ) and across different clustering methods (Table 2). The number and cohesion of second-tier units changed little across season, showing that structural organization at this level was robust against potentially divisive ecological forces.

The effect of season was pronounced on the third and fourth social tiers. In particular, the identification of units in the third social tier was dependent on season, and the cohesion of third-tier units (defined using the wet season definition) was significantly lower during the dry season. This was the only seasonally specific social tier, showing its unique dependence on ecological conditions. The number of units in the fourth tier increased during dry periods, and unit cohesion decreased significantly during these periods. This tier, however, was discernable across the seasons and throughout the study.

Distinguishing the third- from the fourth-tier structure in the dry season, when only one higher social tier was observed, was conducted by assessing the similarity in unit numbers and compositions to results from the total data set; results clearly indicated the presence of the fourth-tier structure rather than the third tier (Table 3). 
Tighter ecological constraints of the dry season thus lead to greater levels of disassociation and splits in higher social units, inhibiting second-tier units from coalescing into third-tier units for extended periods. As competition increases, individuals tend to spatially separate. Levels of association occur along a continuum and the demarcations between social tiers are affected by interactions across all social levels; thus, emergence of one tier can be affected by the state of other tiers. In this case, thirdtier units with bifurcation distance $(d)$ values slightly lower than the third/fourth-tier knot (those which bifurcate just below the knot threshold) were marginally more cohesive than fourth-tier units with $d$ values slightly greater than the knot. Demarcation of these thirdtier units was not possible during the dry season because the rate at which individuals bifurcated in third-tier units, particularly those close to the third/fourth-tier threshold, was not statistically distinguishable from the rate of bifurcation in fourth-tier units (Fig. 4). It is likely that fourth-tier units were affected by the social attraction among the merged third-tier units during the dry season, resulting in the lower knot value of $d$ (Table 3). Such changes affected the stability of fourth-tier units; in this case, some units identified using the total data set split into two dry season fourth-tier units. Essentially, during the dry season, higher-order social units may act as a hybrid between third-tier inhibited relationships and typical fourth-tier associates.

\section{Temporal effects on sociality}

We also found variability in social structure across the study period (Table 3). The thirdtier social delineation was distinguishable in the 1998-2000 data partition, although it was absent in the later half of the study, so comparison between the study periods was not possible. Prior to the start of data collection in June 1998, the El Niño climatic event brought excessive rains to the study area. These excessive rains had a major impact on vegetation growth and it is likely that third-tier units were able to form throughout the year during this period because of the lag effect on vegetation availability acting to supplement typical dry season diminution, thereby limiting intraunit competition for resources. 
Some of the temporal variability observed in social structure may be related to the 2-year sample period of temporal partitions. Elephant reproductive intervals are generally between 3.6 and 4.8 years (Moss, 2001 and Foley, 2002). The reproductive state of breeding females and variability in their calves' ages and development are likely to affect social unit stability. Females with calves less than a year old (those with potentially greater nutritional requirements) may be affected by intragroup competition to a greater extent than other breeding females, resulting in temporarily lower cohesion between these females (first-tier units) and their second-tier units. Alternatively, such females may show periods of increased levels of association to gain antipredation benefits from their social units while the calf is of a susceptible age. Predation by lions, Panthera leo, and humans was a salient cause of mortality in the study population (Wittemyer et al. 2005). Periodic rainfall events like El Niño, which led to the greatest observed population increase during the study period, may extenuate the effects of reproductive status on social unit cohesion by synchronizing reproduction across social units and across the whole population. Longer-term studies may find greater temporal stability if partitions endure for periods matching the population's average interbirth interval.

Population growth, however, is potentially the major factor affecting temporal variability. The number of units in both the second- and fourth tiers increased during the later half of the study, probably in relation to the $4.6 \%$ annual growth rate occurring during the study period (Wittemyer et al. 2005). Structural changes in the numbers of social units as a function of period of study were most obvious among the otherwise stable second-tier social units. The average bifurcation distance (average changes in $d$ ) for second-tier units was the lowest during the 2001-2002 data partition, resulting in six novel second-tier units (Table 3). Interestingly, all six of the new units were composed of single mothers, and their calves, that were subordinate to the matriarch of the group from which they split; three had daughters that were reaching reproductive age or were breeding and three were primiparous. Thus, the effect of unit size on social unit stability appears to be compounded by the age, reproductive state and rank of unit members. 
Social unit stability and composition

Although no evidence was found for an optimal group size for second- or third-tier units, the role and age of the matriarch were found to be salient factors affecting the composition and size of social units (Fig. 5). Potential grandmothers were found to lead larger family units than younger matriarchs. Thus, our results suggest that parous daughters remain with their mothers while their own progeny are sexually immature, leading to three-generation families. Due to the stable linear-dominance hierarchies in elephants (apparently a function of both individual size and age; Moss, 1988 and Foley et al., 2001), intragroup competition disproportionately affects subordinates and their offspring. As females that rank below the matriarchs of their social units become grandmothers, the costs of group philopatry may begin to exceed the benefits derived from remaining with their mothers. Although few females in the study population were of an age at which they were likely to be great grandmothers (i.e. around 50 years old given the generation time of 17.4 years; Moss 2001), those that were of this age did not lead larger social units (mean size $=8$, number of families $=3$ ). Thus, as breeding females become grandmothers, the increased costs of association may cause them to split from their natal social units and form new second-tier social units. Familial contacts can still be maintained through third- or fourth-tier social units while avoiding the costs of high degrees of association.

Previous studies showed a positive correlation between matriarch age and the fitness of social unit members, offering a potential cause for social unit philopatry (McComb et al. 2001). After the death of the matriarch, we observed a second-tier unit fission that resulted in a third-tier unit comprising three novel second-tier units. The social unit was more cohesive before the matriarch's death $(\mathrm{CoC} \pm \mathrm{SE}=0.749 \pm 0.059)$ than after her death $(\mathrm{CoC} \pm \mathrm{SE}=0.658 \pm 0.055)$. This suggests that third and fourth tiers may be generated through fissions of second- and third-tier units, respectively, with the components of the fissioning units retaining stronger ties than expected at random. Furthermore, social unit composition appears to affect higher-order social interactions. Not all second-tier units are members of third-tier units during the wet season, particularly larger second-tier units. Nonforming second-tier units generally had greater 
numbers of breeding females than those that formed third-tier units, although this relationship was not significant at the 0.05 level $\left(\right.$ median $_{\text {nonforming }}=2.5$, median $_{\text {forming }}=6$; Wilcoxon two simple test: $Z=1.778, N_{\text {nonforming }}=12, N_{\text {forming }}=38, P=0.0753$ ). Our observations suggest that third-tier units are most likely to be formed from second-tier units that have recently split as a function of unit size. Higher tier associations may also be formed in response to predation pressures. The largest fourth-tier unit was composed of 17 second-tier units (two to three times more than other units), approximately half of which had recently lost an older breeding female or the unit matriarch. This is in contrast to the other fourth-tier units, of which only one had lost a high-ranking female to natural causes.

Low-ranking primiparous females, experiencing the constraints of calf rearing for the first time, may also split from their natal second-tier social units because of the changing social costs and benefits of child rearing. One of the three primiparous females that formed a novel second-tier unit in the later half of our study left her natal unit after the death of the matriarch, believed to be her mother, but maintained contact with original unit members at third-tier association levels. Such observations provide anecdotal evidence of the benefits of maternal-derived rank and the costs associated with rank alterations for subordinate individuals. Primiparous females were also observed to join non-natal units more frequently than other breeding females, but such visits were usually short lived. Unit switching may serve to enhance the social knowledge of these relatively inexperienced females.

Cohesive and divisive social forces

Inclusive fitness benefits derived from the survival and propagation of kin serve as the general cohesive force in many social organizations (Hamilton, 1964, Vehrencamp, 1983 and Emlen, 1995), although other cooperative benefits from group affiliation, such as enhanced success in territorial or resource defence (Schaller, 1972 and Harcourt, 1992), may serve as the primary cohesive factor and not be based on kinship. Whereas some species may form multitiered social organizations where membership is not stable across years or seasons, elephants are believed to remain in natal units throughout their lives 
(Moss 1988). Genetic studies are needed to elucidate the role of kinship in elephant social structure. Previous studies have provided evidence for inclusive fitness benefits derived from elephant sociality, in the form of allomother effects on calf survivorship (Lee 1987) and fitness benefits relating to matriarch social knowledge (McComb et al. 2001). Our results show that second-tier units, which are probably the units where inclusive fitness benefits are greatest, are highly stable across time and season. This stability indicates that such units are organized below the ecological threshold where variability in the social costs and benefits of units can act to significantly affect unit formation and cohesion (Fig. 6a), although it is apparent that social unit age structure and composition affect where this threshold lies. 

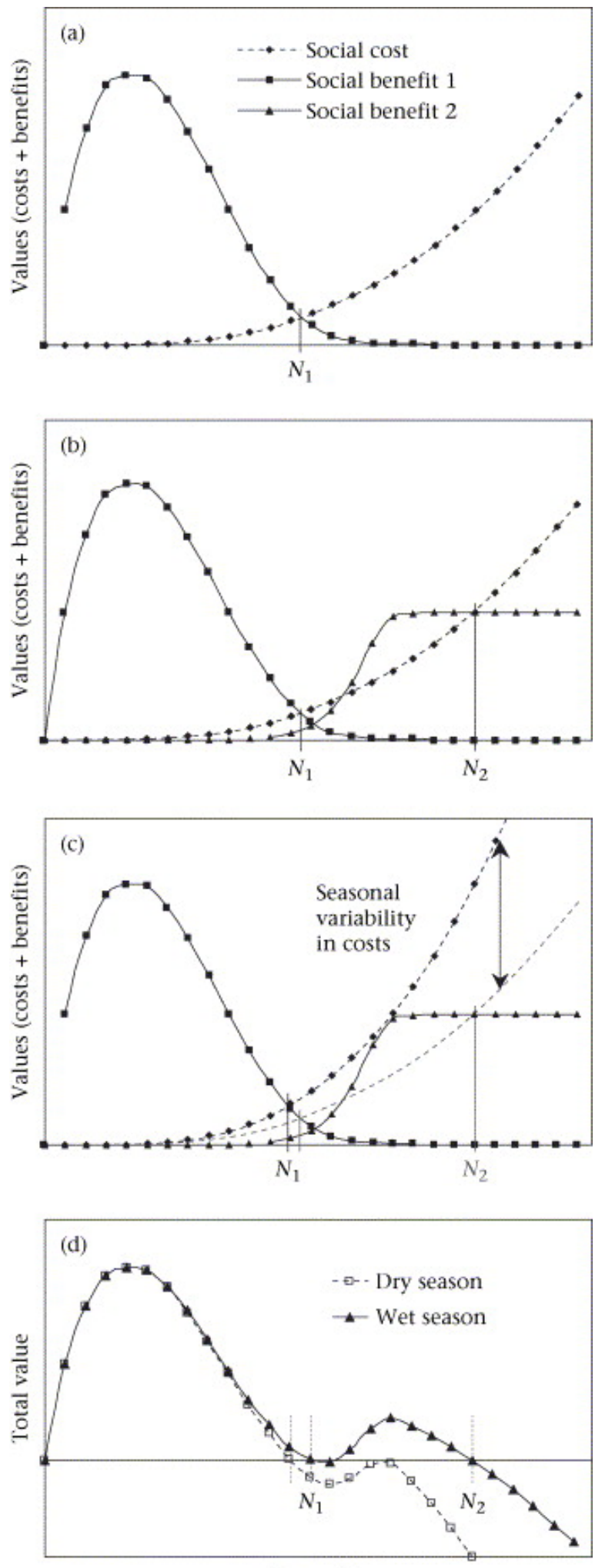

Group size

Figure 6. A conceptual framework of the effects of the interactions among social and ecological costs and benefits on the emergence of a multitiered social organization. (a) 
Social benefit 1 (e.g. inclusive fitness benefits) decreases as group size increases, while a social cost (e.g. feeding competition) increases with group size. The point at which these forces intersect dictates the threshold (maximum, not optimal) size of the social group $\left(N_{1}\right)$, above which costs exceed the benefits of grouping. (b) Combined costs and benefits result in multiple threshold group sizes when certain cohesive or divisive forces are salient at specific group sizes, as with social benefit 2 (e.g. territorial defence for large groups). (c) Costs exceed the benefits of the second-order threshold group size during certain seasonal periods, impeding formation of the higher-order social group during high-cost periods. (d) The net total value of these forces act across the social continuum, and multiple social tiers emerge in relation to a hierarchy of cost/benefit comparisons in which social benefit 1 outranks social benefit 2 .

Expanding the socioecological model to multitiered social systems can help to elucidate the factors affecting the emergence of different social delineations. Our observations indicate that the social benefits derived from multitiered social structure are probably increased inclusive fitness, resource/territorial defence, and antipredatory behaviour. Other researchers have suggested that elephants form clans (probably the equivalent of fourth-tier units) to facilitate the exchange of ecological information (Foley 2002) and to attract mates (Moss \& Poole 1983). Social tiers are influenced by such cohesive and divisive forces, which act throughout the social continuum but may affect relations at each tier to varying degrees (Fig. 6b). In multilevel fission-fusion societies, the nested hierarchy of social tiers can separate into smaller units, down the hierarchy, during times of constraints and increased competition or fuse into larger units, building up the hierarchy, when facilitated by conditions leading to increased cooperative benefits. Social tiers in which the benefits of forming units are approximately equivalent to the costs of forming those units will be unstable in time and space when variability drives costs to exceed the benefits of the group (Fig. 6c). Degrees of social interactions among members in the study population are affected by ecological and temporal variability; delineations (and in some cases emergence of delineations) between social tiers are not fixed but vary over time, both seasonally and with changes in population size. Thus, the net total costs 
change over time and depend on the number of social tiers at which a group is interacting (Fig. 6d).

The formation of higher-order social delineations has important implications for the evolution of social systems. Although studies of multilevelled social structures are few, our study suggests that each tier emerges in response to a different compilation of costbenefit trade-offs (Krause and Ruxton, 2002 and Whitehead, 2003). Furthermore, time spent in different social delineations and their spatial properties (like distances between second-tier units when associating in their third-tier units) potentially affect social benefits derived from multiple social tiers. In gelada baboons, Papio gelada, inclusive fitness benefits apparently act to maintain families (Hamilton, 1964 and Vehrencamp, 1983) but the cohesion of multiple families into a higher social tier may occur in response to predation pressures during periods of increased predation risk (Kummer 1995). Similarly for elephants, individuals are essentially always in their second-tier units, but coalitions of second-tier units to form third-tier units and of third-tier units to form fourth-tier units occur less frequently. Individuals maintain the benefits of their secondtier units, and may incur the benefits while avoiding the costs of third or fourth tiers by coalescing into the higher-order units for limited periods at opportune times. For example, elephants may derive greater social benefits from larger aggregations during the breeding season (coinciding with the wet season) by attracting mates (speculated by Moss \& Poole 1983), which may be the reason individuals coalesce into third-tier units more frequently during wet seasons.

Isolating the function of each social tier is difficult in complex animals like elephants. Our study suggests that as second-tier units increase in size, social costs are likely to cause fissions that create third-tier social units, which can potentially lead to the formation of fourth-tier units through the same process. However, fourth-tier units were apparent across seasons and temporal periods in contrast to third-tier structures, indicating that the dominant forces affecting these two tiers are different. The costs incurred by fourth-tier units may be diffused by the lower levels of cohesion in this tier. Alternatively, novel socioecological benefits, such as intragroup information exchange, 
hypothesized to be the function of clans by Foley (2002), may serve to maintain these units across seasonal periods. It is possible, however, that the fourth-tier social structure is an epiphenomenon, occurring simply as a result of elephants' predisposition to socially interact rather than as a function of socially derived benefits. The levels of cohesion, or time spent with fourth-tier conspecifics, are relatively low, possibly minimizing the ecological costs of such interactions. Thus, fourth-tier sociality may have no functional meaning, representing 'runaway' sociality comparable in an evolutionary context to Fisherian sexual selection (Fisher 1930) or superstimulus responses in mate selection (Basolo 1990). Only with humans is the function of such higher-order delineations clear (e.g. in the context of economic and military alliances; Falger 1992). Kinship can also dictate the formation of higher social levels in humans, as found in pastoralist communities in East Africa where social tiers are based on patriarchal lineage (Spencer, 1965 and Teutsch, 1999). Future controlled experiments are needed to directly assess the influence of cohesive and divisive factors on the formation and structure of different social tiers. Identification of the role and relationships of various social levels can serve to elucidate key socioecological factors affecting a population and is salient to conservation efforts and studies of sociality.

\section{References}

Alexander, 1974 R.D. Alexander, The evolution of social behavior, Annual Reviews of Ecological Systems 5 (1974), pp. 325-383.

Altmann, 1974 S.A. Altmann, Baboons, space, time, and energy, American Zoologist 14 (1974), pp. 221-248.

Basolo, 1990 A.L. Basolo, Female preference predates the evolution of the sword in swordtail fish, Science 250 (1990), pp. 808-810.

Bejder et al., 1997 L. Bejder, D. Fletcher and S. Bräger, A method for testing association patterns of social animals, Animal Behaviour 56 (1997), pp. 719-725.

Buss, 1961 I.O. Buss, Some observations of food and behavior of the African elephant, Journal of Wildlife Management 25 (1961), pp. 131-148. 
Cairns and Schwager, 1987 S.J. Cairns and S.J. Schwager, A comparison of association indices, Animal Behaviour 35 (1987), pp. 1454-1469.

Clutton-Brock and Harvey, 1977 T.H. Clutton-Brock and P.H. Harvey, Primate ecology and social organization, Journal of Zoology 183 (1977), pp. 1-39.

Conner et al., 1992 R.C. Conner, R.A. Smolker and A.F. Richards, Dolphin alliances and coalitions. In: A.H. Harcourt and F.B.M. de Waal, Editors, Coalitions and Alliances in Humans and Other Animals, Oxford University Press, Oxford (1992), pp. 415-443. Cummins, 2000 D.D. Cummins, How the social environment shaped the evolution of mind, Synthese 122 (2000), pp. 3-28.

Devore and Washburn, 1963 I. Devore and S.L. Washburn, Baboon ecology and human evolution. In: F.C. Howell and F. Bourliere, Editors, African Ecology and Human Evolution, Aldine, Chicago (1963), pp. 335-367.

Douglas-Hamilton, 1972 Douglas-Hamilton, I. 1972. On the ecology and behaviour of the African elephant. Ph.D. thesis, University of Oxford.

Dunbar, 1992 R.M. Dunbar, Time: a hidden constraint on the behavioral ecology of baboons, Behavioral Ecology and Sociobiology 31 (1992), pp. 35-49.

Emlen, 1995 S.T. Emlen, An evolutionary theory of the family, Proceedings of the National Academy of Sciences, U.S.A. 92 (1995), pp. 8092-8099.

Emlen and Oring, 1977 S.T. Emlen and L.W. Oring, Ecology, sexual selection and the evolution of mating systems, Science 197 (1977), pp. 215-223.

Falger, 1992 V.S. Falger, Cooperation in conflict: alliances in international politics. In: A.H. Harcourt and F.B.M. de Waal, Editors, Coalitions and Alliances in Humans and Other Animals, Oxford University Press, Oxford (1992), pp. 323-348.

Fisher, 1930 R.A. Fisher, The Genetical Theory of Natural Selection, Clarendon, Oxford (1930).

Foley, 2002 Foley, C. A. H. 2002. The effect of poaching on elephant social systems. $\mathrm{Ph} . \mathrm{D}$. thesis, Princeton University.

Foley et al., 2001 C.A.H. Foley, S. Papageorge and S.K. Wasser, Noninvasive stress and reproductive measures of social and ecological pressures in free-ranging African elephants, Conservation Biology 15 (2001), pp. 1134-1142. 
Freeman, 1992 L.C. Freeman, The sociological concept of group-an empirical test of two models, American Journal of Sociology 98 (1992), pp. 152-166.

Getz, 2003 W.M. Getz, Correlative coherence analysis: variation from intrinsic and extrinsic sources in competing populations, Theoretical Population Biology 64 (2003), pp. 89-99.

Ginsberg and Young, 1992 J.R. Ginsberg and T.P. Young, Measuring association between individuals or groups in behavioural studies, Animal Behaviour 44 (1992), pp. $377-379$.

Gowans et al., 2001 S. Gowans, H. Whitehead and S.K. Hooker, Social organization in northern bottlenose whales, Hyperoodon ampullatus: not driven by deep-water foraging?, Animal Behaviour 62 (2001), pp. 369-377.

Hamilton, 1964 W.D. Hamilton, The genetical evolution of social behaviour. I, II, Journal of Theoretical Biology 7 (1964), pp. 1-52.

Hamilton, 1971 W.D. Hamilton, Geometry for selfish herd, Journal of Theoretical Biology 31 (1971), pp. 295-311.

Harcourt, 1992 A.H. Harcourt, Coalitions and alliances: are primates more complex than non-primates? In: A.H. Harcourt and F.B.M. de Waal, Editors, Coalitions and Alliances in Humans and Other Animals, Oxford University Press, Oxford (1992), pp. 445-472. Hinde, 1976 R.A. Hinde, Interactions, relationships, and social-structure, Man 11 (1976), pp. $1-17$.

Hoogland, 1995 J.L. Hoogland, The Black-tailed Prairie Dog: Social Life of a Burrowing Mammal, University of Chicago Press, Chicago (1995).

Isbell, 1991 L.A. Isbell, Contest and scramble competition: patterns of female aggression and ranging behavior among primates, Behavioral Ecology 2 (1991), pp. 143-155. Jarman, 1974 P.J. Jarman, The social organization of antelope in relation to their ecology, Behaviour 48 (1974), pp. 215-267.

van der Jeugd et al., 2002 H.P. van der Jeugd, I.T. van der Veen and K. Larsson, Kin clustering in barnacle geese: familiarity or phenotype matching?, Behavioral Ecology 13 (2002), pp. 786-790.

Kappeler and van Schaik, 2002 P.M. Kappeler and C.P. van Schaik, Evolution of primate social systems, International Journal of Primatology 23 (2002), pp. 708-738. 
Kerth and Konig, 1999 G. Kerth and B. Konig, Fission, fusion and nonrandom associations in female Bechstein's bats (Myotis bechsteinii), Behaviour 136 (1999), pp. $1187-1202$.

Krause and Ruxton, 2002 J. Krause and G.D. Ruxton, Living in Groups, Oxford University Press, Oxford (2002).

Kummer, 1968 H. Kummer, Social Organization of Hamadryas Baboons, University of Chicago Press, Chicago (1968).

Kummer, 1995 H. Kummer, Quest of the Sacred Baboon, Princeton University Press, Princeton, New Jersey (1995).

Laws, 1966 R.M. Laws, Age criteria for the African elephant: Loxodonta a. africana, East African Wildlife Journal 4 (1966), pp. 1-37.

Laws, 1970 R.M. Laws, Elephants as agents of habitat and landscape changes in East Africa, Oikos 21 (1970), pp. 1-15.

Lee, 1987 P.C. Lee, Allomothering among African elephants, Animal Behaviour 35 (1987), pp. 278-291.

McComb et al., 2001 K. McComb, C. Moss, S.M. Durant, L. Baker and S. Sayialel, Matriarchs as repositories of social knowledge in African elephants, Science 292 (2001), pp. 491-494.

Manly, 1995 B.F.J. Manly, A note on the analysis of species co-occurrences, Ecology 76 (1995), pp. 1109-1115.

Mann et al., 2000 J. Mann, R.C. Connor, P.L. Tyack and H. Whitehead, Cetacean Societies: Field Studies of Dolphins and Whales, University of Chicago Press, Chicago (2000).

Moss, 1988 C.J. Moss, Elephant Memories: Thirteen Years in the Life of an Elephant Family, William Morrow, New York (1988).

Moss, 1996 C.J. Moss, Getting to know a population. In: K. Kangwana, Editor, Studying Elephants, AWF Technical Handbook Series 7, African Wildlife Foundation, Nairobi, Kenya (1996), pp. 58-74.

Moss, 2001 C.J. Moss, The demography of an African elephant (Loxodonta africana) population in Amboseli, Kenya, Journal of Zoology 255 (2001), pp. 145-156. 
Moss and Poole, 1983 C.J. Moss and J. Poole, Relationships and social structure of African elephants. In: R.A. Hinde, Editor, Primate Social Relationships: an Integrated Approach, Blackwell Scientific, Oxford (1983), pp. 315-325.

Myers, 1983 J.P. Myers, Space, time, and the pattern of individual associations in a groups-living species: sanderlings have no friends, Behavioral Ecology and Sociobiology 12 (1983), pp. 129-134.

Omondi et al., 2002 P. Omondi, E. Bitok, O. Kahindi and R. Mayienda, Total Aerial Count of Elephants in Samburu/Laikipia, Kenya Wildlife Service Report, Nairobi, Kenya (2002).

Owen-Smith, 1988 N. Owen-Smith, Megaherbivores: the Influence of Very Large Body Size on Ecology, Cambridge University Press, Cambridge (1988).

Rasmussen et al., in press Rasmussen, H. B., Wittemyer, G. \& Douglas-Hamilton, I. In press. Estimating age of immobilized elephants from teeth impressions using dental silicon. African Journal of Ecology.

Romesburg, 1984 H.C. Romesburg, Cluster Analysis for Researchers, Lifetime Learning, Belmont, California (1984).

van Schaik, 1989 C.P. van Schaik, The ecology of social relationships amongst female primates. In: V. Standen and R.A. Foley, Editors, Comparative Socioecology, Blackwell, Oxford (1989), pp. 195-218.

van Schaik, 1999 C.P. van Schaik, The socioecology of fission-fusion sociality in orangutans, Primates 40 (1999), pp. 69-86.

Schaller, 1972 G.B. Schaller, The Serengietti Lion, University of Chicago Press, Chicago (1972).

Shao and Tu, 1996 J. Shao and D. Tu, The Jackknife and Bootstrap, Springer, New York (1996).

Spencer, 1965 P. Spencer, The Samburu; a Study of Gerontocracy in a Nomadic Tribe,

Routledge \& K. Paul, London (1965).

Strauss, 2001 R.E. Strauss, Cluster analysis and the identification of aggregations, Animal Behaviour 61 (2001), pp. 481-488.

Strier, 2000 K.B. Strier, Primate Behavioral Ecology, Allyn \& Bacon, Boston (2000). 
Takahata et al., 1994 Y. Takahata, S. Suzuki, N. Okayasu and D. Hill, Troop extinction and fusion in wild Japanese macaques of Yakushima Island, Japan, American Journal of Primatology 33 (1994), pp. 317-322.

Terborgh and Janson, 1986 J. Terborgh and C.H. Janson, The socioecology of primate groups, Annual Review of Ecology and Systematics 17 (1986), pp. 111-135.

Teutsch, 1999 F. Teutsch, Collapsing Expectation: National Identity and Disintegration of the State of Somalia, Centre of African Studies, Edinburgh University, Edinburgh (1999).

Trivers, 1972 R.L. Trivers, Parental investment and sexual selection. In: B. Campbell, Editor, Sexual Selection and the Descent of Man, 1871-1971, Aldine, Chicago (1972), pp. 136-179.

Vehrencamp, 1983 S.L. Vehrencamp, A model for the evolution of despotic versus egalitarian societies, Animal Behaviour 31 (1983), pp. 667-682.

Whitehead, $1995 \mathrm{H}$. Whitehead, Investigating structure and temporal scale in social organizations using identified individuals, Behavioral Ecology 6 (1995), pp. 199-208. Whitehead, 1997 H. Whitehead, Analysing animal social structure, Animal Behaviour 53 (1997), pp. 1053-1067.

Whitehead, 1999 H. Whitehead, Programs for analyzing social structure. SOCPRGO 1.2 (1999) (http://is.dal.ca/ whitelab/index.htm).

Whitehead, 2003 H. Whitehead, Sperm Whales: Social Evolution in the Ocean, University of Chicago Press, Chicago (2003).

Whitehead and Dufault, 1999 H. Whitehead and S. Dufault, Techniques for analyzing vertebrate social structure using identified individuals: review and recommendations, Advances in the Study of Behavior 28 (1999), pp. 33-74.

Wittemyer, 2001 G. Wittemyer, The elephant population of Samburu and Buffalo Springs National Reserves, African Journal of Ecology 39 (2001), pp. 357-365.

Wittemyer et al., 2005 G. Wittemyer, D.K. Daballen, H.B.R. Rasmussen, O. Kahindi and I. Douglas-Hamilton, The demographic status of the Samburu elephant population, African Journal of Ecology 43 (2005), pp. 44-47. 
Wrangham, 1980 R.W. Wrangham, An ecological model of females-bonded primate groups, Behaviour 75 (1980), pp. 262-300.

Correspondence: G. Wittemyer, University of California at Berkeley, Department of Environmental Science, Policy, and Management, 201 Wellman Hall, Berkeley, CA 94720-3112, U.S.A.

${ }^{1}$ I. Douglas-Hamilton is at Save the Elephants, P.O. Box 54667, Nairobi, Kenya.

${ }^{2}$ W. M. Getz is at the Mammal Research Institute, Department of Zoology and Entomology, University of Pretoria, Pretoria 0002, South Africa. 